\title{
АКТУАЛЬНЫЕ ПРОБЛЕМЫ ПРОФЕССИОНАЛЬНОГО СОПРОВОЖДЕНИЯ И САМООПРЕДЕЛЕНИЯ УЧАЩИХСЯ
}

Работа выполнена при поддержке Государственного комитета по науке МОН РА в рамках научного проекта N18T-5A056

Папоян В.Р., Саргсян Д.Ю., Галстян А.С. (Ереванский государственный университет, Ереван, Армения) vpapoyan@ysu.am,dianasargsyan@ysu.am, alina.galstyan@ysu.am 乙tinlujugúuir múu. 31.07.2021

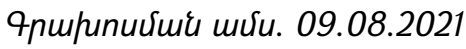

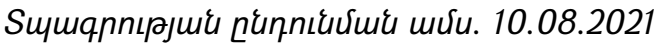

Статья посвящена самоопределению юношей, становлению их личности. Приведены личностные характеристики, которые способствуют эфрфективности учебной деятельности. При психологическом сопровождении и самоопределении приведены как внешние, так и внутренние фракторы, обеспечивающие становление будущих специалистов. Разработана и представлена по этапам технология психологического сопровождения. Помимо личностных особенностей, самоопределения, которые обеспечивают эффективность дальнейшей трудовой деятельности, наиболее важными для специалистов являются реалистические представления об их профессиональной деятельности и компетенции. Подробно рассматривается профессиональная компетентность, которая включает углубленные профессиональные знания.

Ключевые слова: самоопределение, профессиональное сопровождение, компетентность, консультирование, профессионализм, технологии.

DOI: https://doi.org/10.46991/SBMP/2021.4.2.260

Современный этап развития общества диктует глубокие изменения во всех сфрерах жизнедеятельности, что оставляет существенное влияние на жизнедеятельность будущих специалистов. Значительные перемены, которые наблюдаются как на макро-, так и на микроуровне, оказывают существенное влияние на индивидуальную жизнь людей. Процессы социальной трансформации общества непосредственно отражаются на состоянии системы образования. Заметно усилилось внимание к вопросам качества образования на всех уровнях: от школы до ВУЗа.

Актуальность проблемы обеспечивается тем, что профессиональное сопровождение и самоопределение являются основной предпосылкой становления личности, и, следовательно, развития общества в целом. Выбор 
профессии, профессиональное самоопределение в юношеском возрасте оказывают свое влияние на деятельность человека, обеспечивая его личностное развитие, формирование его мотивационно-ценностной сферы, предопределяя векторную направленность качества жизни человека. Справедливо высказывание Е.Климова, что «профессия - это судьба, жизненный путь человека,...это и образ жизни, и образ мыслей, и стереотипы восприятия мира, и социальный тип человека» [1, с.65, 4, с.372]. Структура профессионального самоопределения представлена рядом конкретных компонентов, своевременная оценка которых путем психологического сопровождения поможет самореализации, профессиональному становлению и росту личности. Отмеченная проблема актуальна, как для выпускников высших учебных заведений, так и для старшеклассников, стоящих перед проблемой выбора гуманитарно-ориентированного или естественно-научного направления, для получения дальнейшего образования.

Профрессионализация личности представляет собой поэтапный процесс. Формирование профессиональных намерений, предпочтение и выбор профессии рассматриваются в качестве начального этапа профессионального становления личности и оказывают влияние на профессиональное самоопределение. Ряд личностных характеристик, таких как контроль поведения, совестливость, адекватное отношение к окружающим и общительность, которые значимы для юношеского возраста, способствуют эфффективности учебной деятельности в случае четкой профессиональной ориентации. К наиболее важным компонентам самореализации в этом возрасте относят устойчивые ценности, потребность к познанию, креативность и аутосимпатию. В процессе психологического сопровождения и профессионального самоопределения молодежи используют такие технологии, которые способствуют фрормированию эффективного психологического портрета будущего специалиста, развитию профессиональных важных качеств, адекватному осознанию представлений о профессии и повышению уровня самосознания личности. Цель нашего исследования заключается во внедрении разработанных нами технологий психологического сопровождения при выборе профессии. Под технологией психологического сопровождения мы будем понимать совокупность мероприятий, направленных на формирование профессионального самоопределения оптантов, развитие и реализацию их внутреннего потенциала.

При психологическом сопровождении важно учесть и оценить внешние факторы: семья (степень образования, социальный статус, атмосфрера), социальная среда (место жительства, учебное заведение и т.д.), взаимоотношения (авторитетные личности, способствующие формированию 
системы ценностей, СМИ) и внутренние фракторы: личностные качества, способности, самоотношение и самооценка (рис.1).

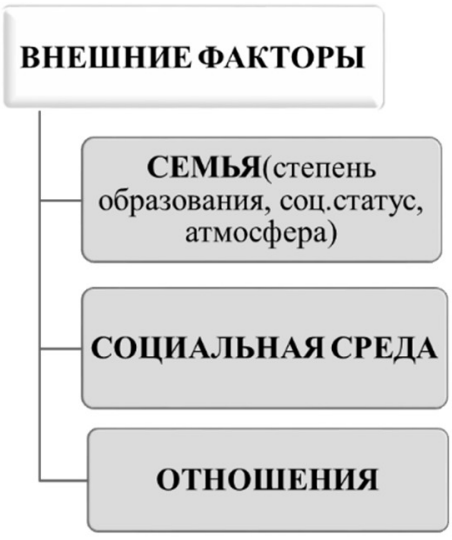

\section{ВНУТРЕННИЕ ФАКТОРЫ}

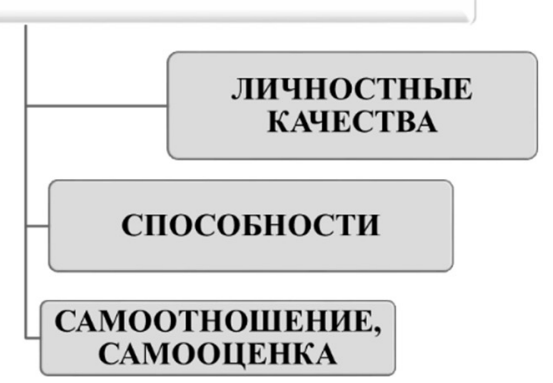

Рис. 1. Факторы обеспечивающие эффрективность психологического сопровождения

На настоящем этапе многие профессии теряют свою актуальность, уступая свое место востребованным, современным специальностям на рынке труда, что, в свою очередь, раскрывает новые перспективы для других специализаций. Не исключено, что многие специалисты, по разным причинам, не имея возможности самореализации в данной области, становятся перед выбором новых профессий. Среди причин следует выделить:

- динамику развивающего общества, когда теряется актуальность и спрос профрессии,

- применение новых инновационных технологий,

- наличие междисциплинарных связей,

- влияние микро- и макро- среды,

- недостаточно сорормированную склонность к предпринимательству,

-насыщенность информационной рекламы вокруг той или иной профессии посредством СМИ и т.д.

Особое место в психологическом сопровождении профессионального становления личности занимает профессиональное консультирование, главная цель которого оказание психологической помощи при выборе профессии. Профрконсультирование - это индивидуальный подход, психологическая работа по оказанию помощи конкретному учащемуся, находящемуся в неопределенности при выборе профессии [5]. В разрабатываемой нами технологии психологического сопровождения в рамках профессионального психологического консультирования мы старались придерживаться игровой формы работы с оптантами: могу, хочу, нужно. 
Исходя из результатов наших исследований целесообразно для профрессионального самоопределения разработать технологию психологического сопровождения по следующим этапам:

$\checkmark$ формирование реальных представлений о профессиональном самоопределении,

$\checkmark$ компетентное информирование о данной профессии в общей системе профессий,

$\checkmark$ выявление внешней и внутренней мотивации профессионального самоопределения,

$\checkmark$ определение социально-экономических и бытовых условий жизнедеятельности,

$\checkmark$ комплексное исследование индивидуальных особенностей личности,

$\checkmark$ определение адекватности самопознания, самооценки и уровня притязаний личности,

$\checkmark$ обоснование реального и идеального представления о данной профессии,

$\checkmark$ сопоставление требований $к$ профессиональной деятельности и ценностной системе личности.

Поэтапную работу, с применением психологических технологий, можно представить следующим образом:

1. профрессиональное самоопределение и разработка индивидуального плана,

2. оценка уровня притязания и профессиональных достижений посредством тестирования и сотрудничества с педагогами,

3. психодиагностика личностных качеств, способностей, ценностных ориентаций, интересов, мотивации,

4. беседа, интервью, биографические данные, анализ семейной атмосферы с помощью анкетирования.

Для будущих специалистов, помимо личностных особенностей, адекватной оценки и сопровождения, которые обеспечивают эфффективность дальнейшей трудовой деятельности, наиболее важными являются реалистические представления об их профессиональной деятельности; приобретение знаний в процессе учебной деятельности; овладение профессиональными компетенциями и удачный опыт престижных специалистов, работающих в этой области (рис. 2).

$\checkmark$ Немаловажными являются следующие предпосылки, которые обеспечивают процесс профессионального образования, выбора работы и компетентность:

$\checkmark$ образование, соответствующие знания,

$\checkmark$ представления о дальнейшей профессиональной области,

$\checkmark$ представления о возможной деятельности на рынке труда, 
$\checkmark$ оценка собственных возможностей и способностей, связанных с приобретением профессиональных навыков,

$\checkmark$ сведения о потребности, спросе профессиональных кадров,

$\checkmark$ оценка перспективы профессионального роста и внутренних ресурсов на основе самопознания и собственного опыта.

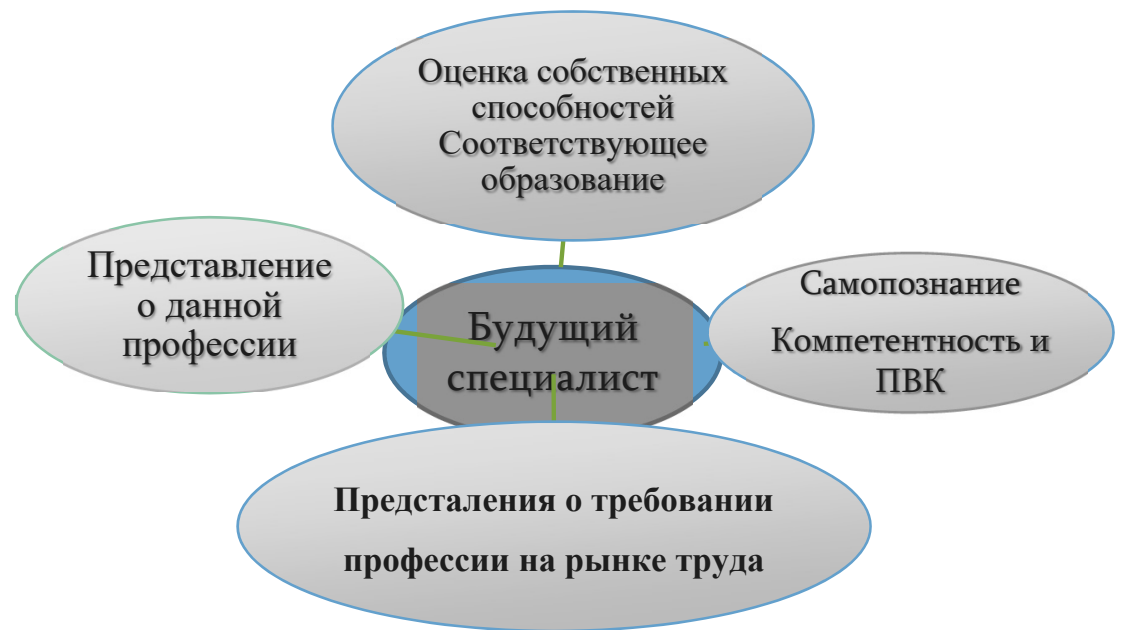

Рис. 2. Обеспечение эфрфективности будущего специалиста

Профессиональная компетентность включает углубленные профессиональные знания и рассматривается как характеристика качеств подготовки специалиста, потенциала эффрективности в профессиональной деятельности. Профессиональную компетентность молодежи возможно обеспечить путем стимулирования их самостоятельности. Она является необходимой составляющей профессионализма и формируется в процессе профрессиональной подготовки через умения, способности и личностные качества. Исследуя личностно-социальные качества будущих специалистов, необходимо выделить такие, с помощью которых возможно преодолеть трудности на пути становления профессионала. С помощью знаний, навыков и компетенций, молодые специалисты, достигшие высоких результатов, исходя из собственных стремлений, могут раскрыть пути для новой карьеры и самоактуализации.

Профрессиональная компетентность включает следующие составные компоненты :

-когнитивно-интеллектуальные,

-коммуникативные,

-мотивационно-определяющие [3].

Формируя профессиональную компетентность через позитивную мотивацию среди молодежи, можно достичь стимулированию как внутренних 
(профессиональный рост, самообразование, стремление к саморазвитию, потребность в приобретении знаний, эстетическая удовлетворенность от работы), так и внешних (высокая зарплата, уважение среди коллеги и т.д.) факторов.

Структурно профессиональную компетентность можно представить следующим образом:

$\checkmark$ социально-правовое (овладение навыками общения и коммуникации, профессиональным мастерством),

$\checkmark$ специальное (самообразование, самотренировка, самостоятельное решение профессиональных задач, адекватная оценка собственной работы),

$\checkmark$ индивидуальная(профессиональный рост, потребность и возможность квалификации),

$\checkmark$ ауто (адекватное представление профессиональных качеств и страхование от профессионального утомления, деформации),

$\checkmark$ внеочередное (способность преодолеть внезапные трудности, возникшие во время трудовой деятельности).

Обеспечение компетенции путем стимулирования самостоятельности среди юношей и молодежи представлено в виде информированности следующим путем [2]:

$\checkmark$ раскрытие способностей, возможностей и интересов,

$\checkmark$ обеспечение и соответствие дальнейших планов для вышеуказанных целей,

$\checkmark$ сведение о будущей профессии для оценки пригодности данной специальности и специалиста,

$\checkmark$ осознание профессиональной компетенции в результате оценки собственных способностей и возможностей,

$\checkmark$ осведомленность о будущей специальности и о ее спросе,

$\checkmark$ исследование рынка труда молодежью,

$\checkmark$ предложение новых идей,

$\checkmark$ планирование действий для осуществления идеи,

$\checkmark$ оценка конкуренции и введение пояснений в запланированные действия,

$\checkmark$ представления о возможных путях профессионального и финансового сотрудничества.

Вышеотмеченные действия возможно представить в виде следующих группировок (рис.3). 


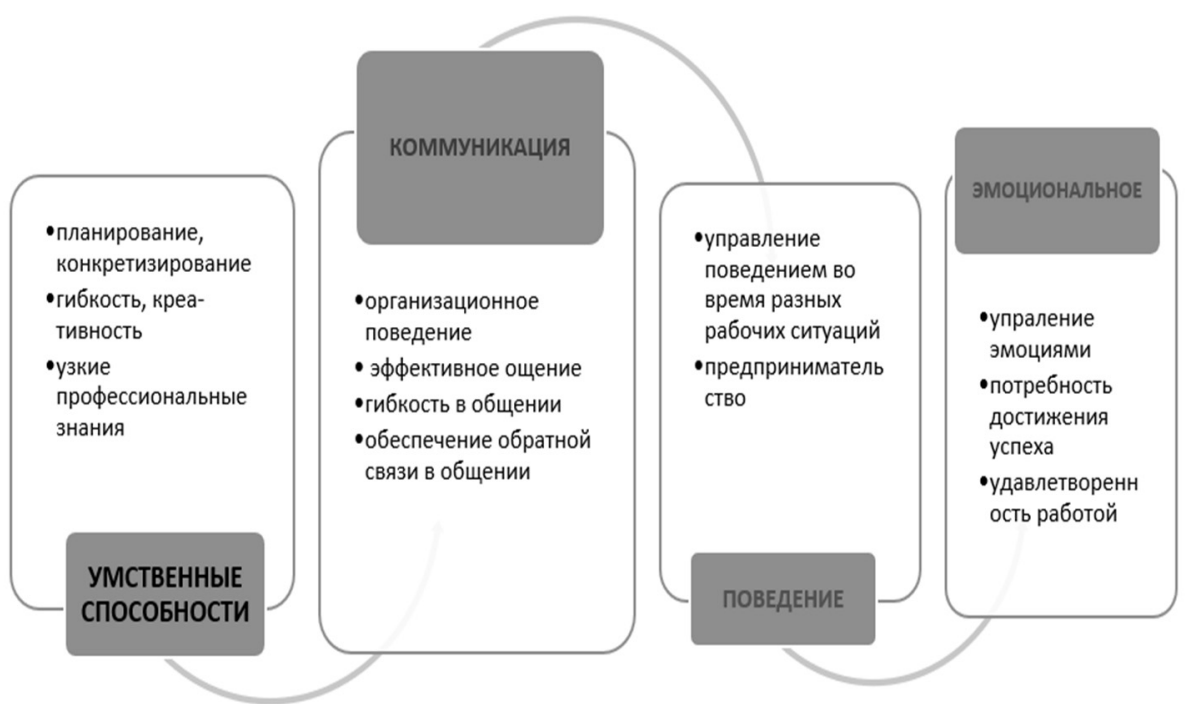

Рис. 3. Личностные и профессиональные качества, обеспечивающие самостоятельность будущего компетентного специалиста

С точки зрения психологической оценки личности, поэтапная перспектива процесса формирования образовательных намерений учащегося охватывает самые близкие достижимые цели до мечты о будущем. Завершение любого этапа обучения предполагает новый выбор, продолжение и новое понимание преемственности $и$ новую цель, которая в дальнейшем послужит профессиональной подготовке и трудовой деятельности.

Этапы достижения целей:

- этап постановки цели - самооценка и цели личности учащегося,

- этап осознания цели - цели образования; осознание знаний, умений и собственных возможностей; жизненные цели,

- этап осуществления цели - завершение образования; профессиональные цели; работа; прогресс; саморазвитие; социальный статус.

В заключение, мы хотим подчеркнуть тем самым, что профессиональное образование является важным базовым компонентом профессиональной подготовленности. В то же время, своевременное сопровождение, самоопределение, оценка собственных возможностей, самостоятельность, компетентность и предпринимательство обеспечат осознание профессионального становления молодежи $и$ ее отношение к профессиональному образованию как к непрерывному процессу. Для достижения наших целей разработаны программы и методики, которые обеспечивают знания о данной профессии, идентификацию с профессией и требования к ней [6]. 
Разработанные нами методики и технологии психологического сопровождения была применены с психологами, социальными работниками и учителями разных школ и получили прикладное значение в их дальнейших работах с учащимися.

\title{
Литература
}

1. Папоян В.Р., Мурадян Е.Б.,Галстян А.С. Психологическое сопровождение как эфрфективная форма профессионального самоопределения старших школьников, ЕГУ, Банбер N1 (16), Ереван, 2015, с.65-72.

2. Папоян В.Р., Мурадян Е.Б.,Галстян А.С. Самостоятельность в контексте профессиональной компетентности личности, Актуальная психология Научный вестник Ереван 2017г, Армения, с. 561-567.

3. Безюлева Г.В., Иванова Н.В., Никитин М.В., Шеламова Г.М. Профрессиональная компетентность: аспекты формирования /Под ред. Г.В. Безюлевой.-М, Московский психолого-социальный институт, Федеральный институт развития образования, 2005 - 82 с.

4. Климов Е.А. Психология преофессионала. М.,1996, с.372

5. Папоян В.Р., Мурадян Е.Б.,Галстян А.С. Психологическое сопровождение как эффективная форма профессионального самоопределения старших школьников., в пособии “Психологическое сопровождение профессионального самоопределения и становления в системе образования", ЕГУ, 2015, с. 49.

6. Папоян В.Р., Галстян А.С., Саргсян Д.Ю., Карапетян М.А., Психологическое оценивание подготовки специалиста. Тесты и упражнения, (на арм. языке), ЕГУ, Ереван, 2020, 198 с.

7. Профессиональное самоопределение и карьерное консультировани, https://studme.org/1486011028074/psihologiya/professionalnoe_samoopre delenie_karernoe_konsultirovanie"

\section{ACTUAL PROBLEMS OF PROFESSIONAL SUPPORT AND SELF- ORIENTATION OF STUDENTS}

\author{
Papoyan V.R., Sargsyan D.Yu., Galstyan A.S. (Yerevan State University,
} Yerevan, Armenia)

The article is devoted to the self-determination of young men and the formation of their personality. It presents the personal characteristics that contribute to the effectiveness of educational activities. By psychological support and selfdetermination, external and internal factors are given, that ensure the formation of 
future specialists. The technology of psychological support has been developed and presented by stages. In addition to personal characteristics and self-determination, which ensure the effectiveness of further working activity, the most important for specialists are realistic ideas about their professional activities and competence. Professional competence is considered in detail, which includes in-depth professional knowledge.

Keywords: self-determination, professional support, competence, consulting, professionalism, technology.

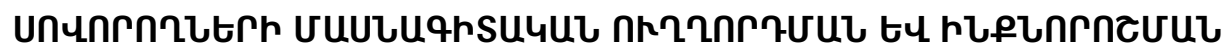

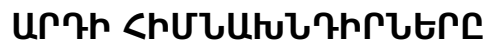

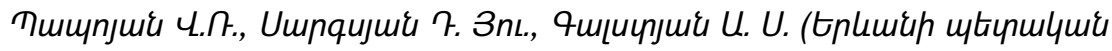

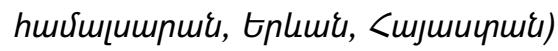

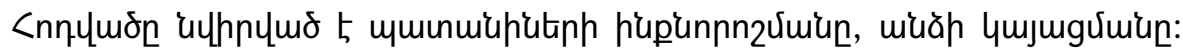

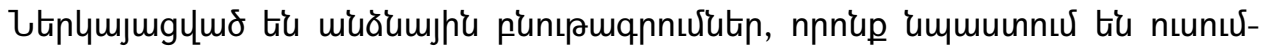

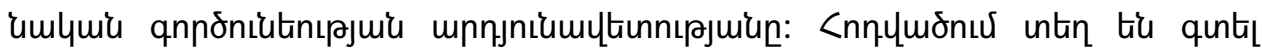

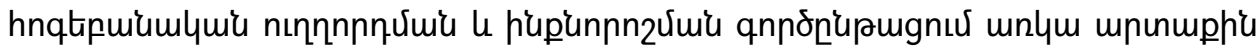

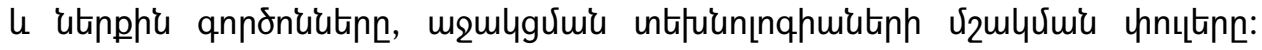

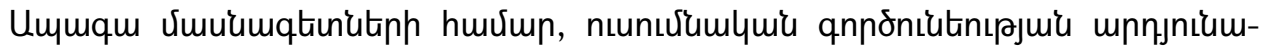

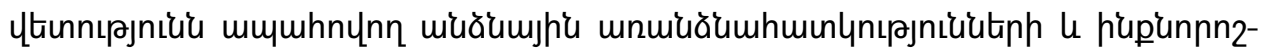

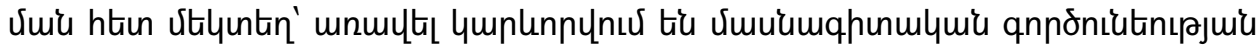

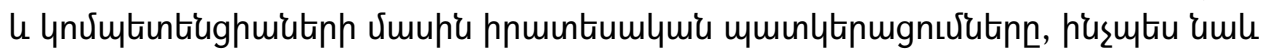

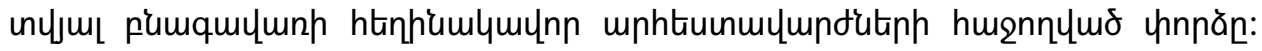

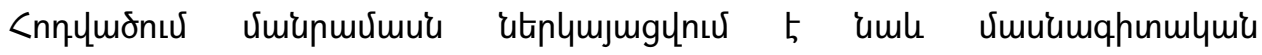

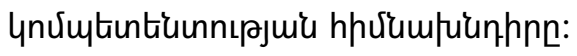

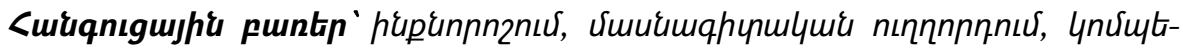

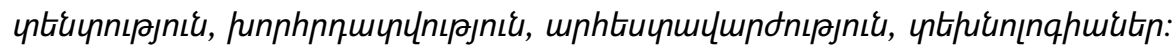

